\title{
DESIGN AND FATIGUE ANALYSIS OF MULTI CYLINDER ENGINE AND ITS STRUCTURAL COMPONENTS
}

\author{
S. Sathishkumar' ${ }^{1}$ M. Kannan ${ }^{2}$ \\ ${ }^{1}$ Assistant Professor, Vel Tech-Avadi, Chennai-600062, Tamil Nadu, India \\ ${ }^{2}$ Professor, MAM College of Engineering, Trichy- 621105, Tamil Nadu, India \\ *Corresponding Author Email: kssathishkumar.93@gmail.com
}

This is an open access article distributed under the Creative Commons Attribution License, which permits unrestricted use, distribution, and reproduction in any medium, provided the original work is properly cited

\section{ARTICLE DETAILS}

\section{Article History:}

Received 12 November 2017 Accepted 12 December 2017 Available online 1 January 2018

\begin{abstract}
The connecting rod is the main moving parts and an important component of engine. If the reliability is not strong enough, fatigue failure of the connecting rod would occur, thereby leading to component fracture and engine failure. So much so that connecting rod fracture. It will way to engine fault as well as serious outcome. In this paper, stress distribution and fatigue life of connecting rod in heavy vehicle engine were parametric model of Connecting rod is modeled using CATIA V5 R20 software and to that model, analysis is carried out by using ANSYS 11.0 Software. Finite element analysis of connecting rod is done by considering the materials of carbon steel. The results showed that the medial surface of small end will be the critical surface whereby damage will initiate at the maximum stretch condition. The critical location is at the transition area between the big end and connecting shank at maximum compression condition. In this paper, stress distribution and fatigue life of connecting rod in heavy vehicle engine were analyzed using the commercial 3D finite element software ANSYS.
\end{abstract}

\section{KEYWORDS}

Connecting Rod, Piston, CATIA, ANSYS, Stress, Fatigue.

\section{INTRODUCTION}

Internal combustion engine is one of the energy sources in automobile industry. IC engine converts chemical energy into mechanical energy in the form of reciprocating motion of piston. Crankshaft and connecting rod convert reciprocating motion into rotary motion. Connecting rod is one of the important driving parts of light vehicle and heavy vehicle engine [1]. The con rod expressed on various forces of piston acceleration and deceleration from the stroking motion, loads generated by friction and the load by the cylinder pressure during the combustion stroke. Under normal operating condition the design of the connecting rod for infinite (not defined) number of cycles is based on these forces such that designed connecting rod does not exceed the desired strength during the life span. If it is not strong enough, fatigue failure of the connecting rod would occur, thereby leading to component fracture and engine failure. So much so that connecting rod fracture. It will lead to engine fault as well as serious outcome [2]. Experimental stress analysis can also be used to calculate the stresses which will provide more reasons to compare the different values obtained. As an effective analysis method, finite element analysis has been used widely in the design of connecting rod.

Finite Element Analysis (FEA) technology was first developed in 1943 by R. Courant, who utilized the Ritz method of numerical analysis and minimization of variation calculus to obtain approximate solutions to vibration systems [3]. Shortly thereafter, a paper published in 1956 by M. J. Turner, R. W. Clough, H. C. Martin, and L. J. Top established a broader definition of numerical analysis. The paper centered on the "stiffness and deflection of complex structures". By the early 70's, Finite Element Method was limited to expensive mainframe computers generally owned by the automotive, aeronautics, defense \& nuclear industries. Since the rapid decline in the cost of computers and the phenomenal increase in computing power, FEA has been developed to an incredible precision [4]. Present day supercomputers are now able to produce accurate results for all kinds of parameters.

FEA consists of a computer model of a design that is stressed and analyzed for particular results. It is most widely used to design of new product and also existing product refinement. A company is able to verify a proposed design will be able to perform to the client's requirements prior to manufacturing. Modifying an existing product and its structure is utilized to qualify the product or structure for a new service condition [4]. If it is possible of structural failure, FEA method may be used to help determine the design modifications to meet the new condition.

\subsection{Problem Description}

Connecting rod is one of the most significant components internal combustion engines bearing the statically and dynamically fluctuating loads. For the analysis of I.C engine connecting rod the most critical area is consider and accordingly two dimensional of connecting rod is formed [5]. Pressure load is acting on the small end of the connecting rod. Pressure load is calculated by using joint force calculated in ADAMS simulation software. Big end of the connecting rod is fixed, and small end is free. The maximum pressure acting on the small end is $108.733 \mathrm{~N} / \mathrm{mm} 2$ (force $=19205 \mathrm{~N}$ ) and minimum pressure acting on the small end is $84.2009 \mathrm{~N} / \mathrm{mm} 2$ (force=14871.984). With the help of the stress acting on the small end going to calculate a van misses stress and factor of safety.

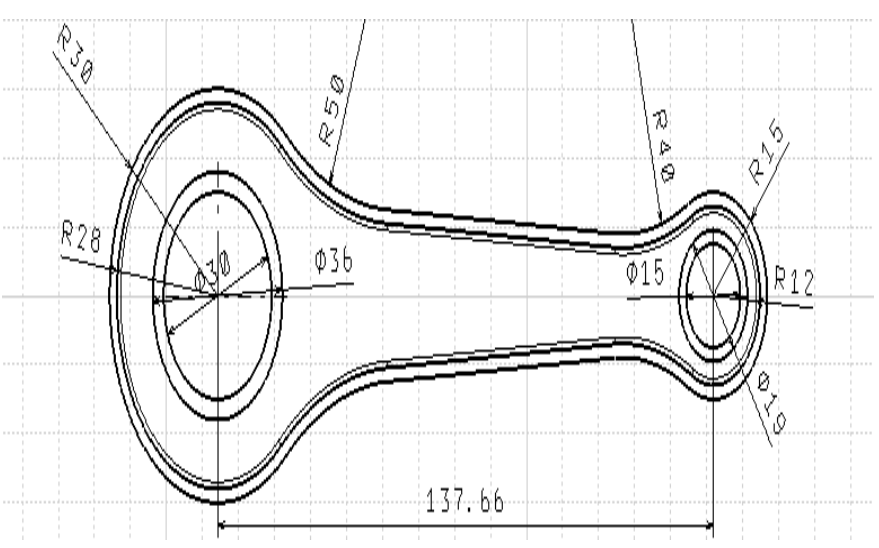

Figure 1: Design Calculation of Connecting Rod 
Length of the connecting rod $=137.66 \mathrm{~mm}$

Inner radius of the large end $\quad=15 \mathrm{~mm}$

Outer radius of the large end $=30 \mathrm{~mm}$

Inner radius of the small end $\quad=7.5 \mathrm{~mm}$

Outer radius of the small end $=15 \mathrm{~mm}$

Gas flow equation is PV $=\mathrm{mRT}$

Where

$\mathrm{V}=$ volume

$\mathrm{R}=$ gas constant

$\mathrm{T}=$ temperature

? $\mathrm{p}=13.445 \mathrm{mpa}$

Maximum explosive pressure in piston $(\mathrm{P})=13.44 \mathrm{mpa}$

Crank radius $r$

$=$ stroke of piston $=32.5 \mathrm{~mm}$

Angular speed $(\mathrm{w})=\underline{60}=157.1 \mathrm{rad} / \mathrm{sec}$

Force on the connecting rod $=\mathrm{Fp}-\mathrm{F}$

Where

$\mathrm{F}_{\mathrm{p}}=$ Force on the piston pin

$\mathrm{F}=$ Force on the reciprocating parts

$\mathrm{F}=\underline{1000 \mathrm{WrV}^{2}}+\cos \theta \underline{\operatorname{Cos} 2 \theta}$

$$
\text { gr } n
$$

Where

$\mathrm{Wr}=\mathrm{mg}=$ weight of the reciprocating parts $=2 \times 9.81=19.62 \mathrm{~N}$

$\mathrm{R}=$ crank radius $=32.5 \mathrm{~mm}$

$\theta=$ crank angle from the dead centre

$\mathrm{g}=$ acceleration due to gravity $=9.81 \mathrm{~m} / \mathrm{sec}^{2}$

? $\mathrm{F}=4555 \mathrm{~N}$

Total force on the connecting rod

$\mathrm{Fc}=23.76 \times 10^{3}-4555$

$=19205 \mathrm{~N}$

Pressure acting on the connecting rod

$\mathrm{P}=\mathrm{Fc} / \mathrm{A}$

国 $\mathrm{P}=108.733 \mathrm{~N} / \mathrm{m}$

\section{MATERIALS}

1. Carbon Steel

2. Aluminum Alloy

3. Alloy Steel

\subsection{Property of Material}

\begin{tabular}{|c|c|c|c|c|}
\hline S.NO & Properties & Carbon Steels & Alloy Steels & Aluminum Alloy \\
\hline 1 & Density $\left(1000 \mathrm{~kg} / \mathrm{m}^{3}\right)$ & 7.85 & 7.85 & $2.6-2.8$ \\
\hline 2 & Elastic Modulus (GPa) & $190-210$ & $190-210$ & 70-79 \\
\hline 3 & Poisson's Ratio & $0.27-0.3$ & $0.27-0.3$ & 0.33 \\
\hline 4 & Thermal Expansion $\left(10^{-6} / \mathrm{K}\right)$ & $11-16.6$ & $9.0-15$ & - \\
\hline 5 & Melting Point $\left({ }^{\circ} \mathrm{C}\right)$ & & & 660 \\
\hline 6 & Thermal Conductivity (W/m-K) & $24.3-65.2$ & $26-48.6$ & - \\
\hline 7 & Specific Heat (J/kg-K) & $450-2081$ & $452-1499$ & - \\
\hline 8 & Electrical Resistivity $\left(10^{-9} \quad-\mathrm{m}\right)$ & $130-1250$ & $210-1251$ & - \\
\hline 9 & Tensile Strength (MPa) & $276-1882$ & $758-1882$ & $230-570$ \\
\hline 10 & Yield Strength (MPa) & 186-758 & $366-1793$ & $215-505$ \\
\hline 11 & Percent Elongation (\%) & $10-32$ & 4-31 & $10-25$ \\
\hline 12 & Hardness (Brinell 3000kg) & $86-388$ & $149-627$ & - \\
\hline
\end{tabular}

\section{COMPONENT DESIGN}

\subsection{Introduction of CATIA}

CATIA V5 is a feature based, parametric solid modeling program. As such it's use is significantly different from conventional drafting programs. In conventional drafting (either manual or computer assisted), various views of a part are created in an attempt to describe the geometry [6]. Each view incorporates aspects of various features (surfaces, cuts, radii, holes, protrusions) but the features are not individually defined. In featurebased modeling, each feature is individually described then integrated into the part. However, other resilient materials, e.g. polymers, where special properties such as a low modulus and high internal damping capacity are required used later. In general terms, shock absorbers help cushion cars on uneven roads.

\subsection{Part Designs}

\subsubsection{Piston}

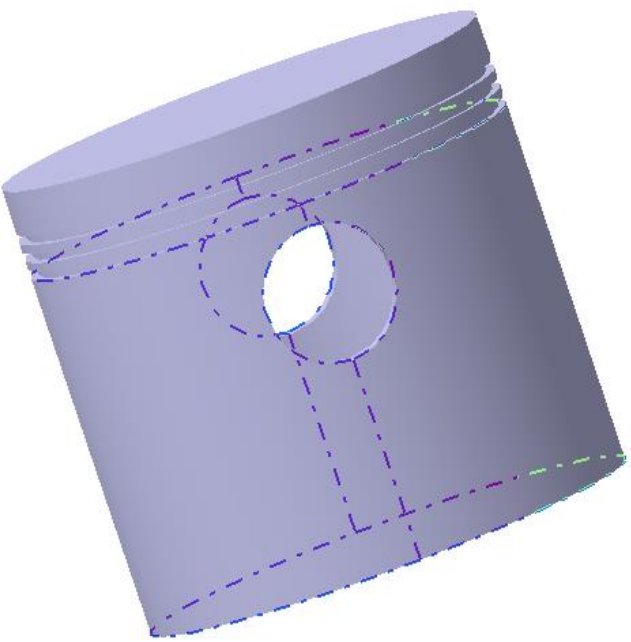

Figure 2: Piston Model

\subsubsection{Connecting Rod}

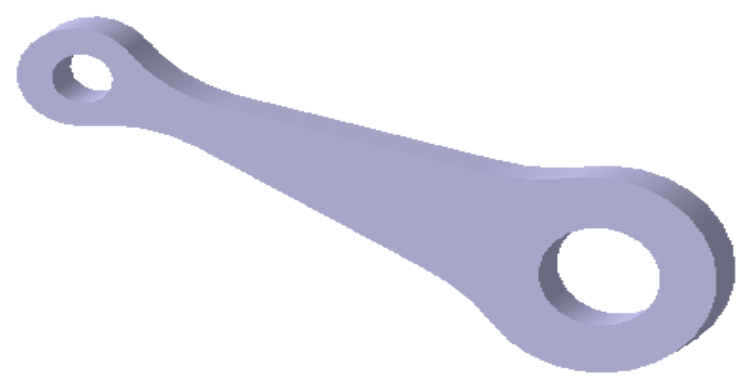

Figure 3: Connecting rod Model

3.2.3 Gudgeon Pin

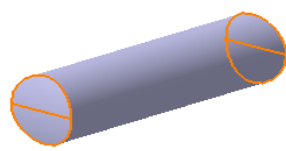

Figure 4: Gudgeon pin Model 


\subsubsection{Crank Shaft}

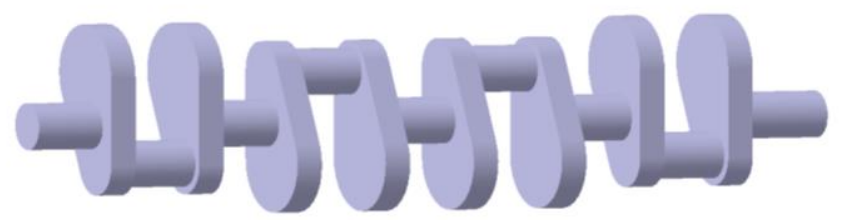

Figure 5: Crank shaft Model

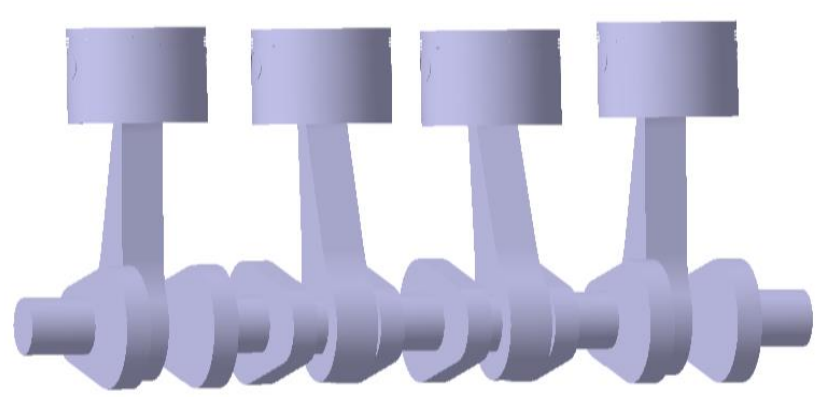

Figure 6: Assembling view

\section{DESIGN ANALYSIS}

\subsection{Determination of load carrying forces by using ADAMS}

In kinematics involves in finding out the results of body in motion without considering the forces and dynamics involves in finding the result of the body in motion with considering the forces. The choice of approach to the solution is depend on the problem at hand and the available data.

In general mechanisms are used to obtain various types of motion, one of the motion is intermittent motion, to obtain the intermittent motion various type of mechanisms are used out of which cam mechanism provides the best intermittent motion is been explained in the ADAMS by comparing the advantage of cam over the other mechanism.

Behalf of Kinematics operation the wiper function is based on four bar crank mechanism were to obtain the crank rocker motion synthesis of link length is carried out and modeled in ADAMS [7]. The constrains are provided the result of displacement $(\mathrm{m} / \mathrm{s})$, velocity $(\mathrm{m} / \mathrm{s})$ and acceleration $\left(\mathrm{m}^{2} / \mathrm{s}\right)$ is taken and the effect of change in result by changing the crank length and coupler length is funded and the results were compared and analyzed. In the given mass, radius \& speed the shape is modeled in ADAMS and the force acting on the bearing was found and by changing the parameters of mass, radius and speed the effect of change in the result was found and it is compared and analyzed.

\subsection{Data value found from the ADAMS software}

Load acting on the piston (pressure) $=13.445 \mathrm{mpa}$

Force transmitted to the connecting rod (small end) $=19203.3 \mathrm{~N}$

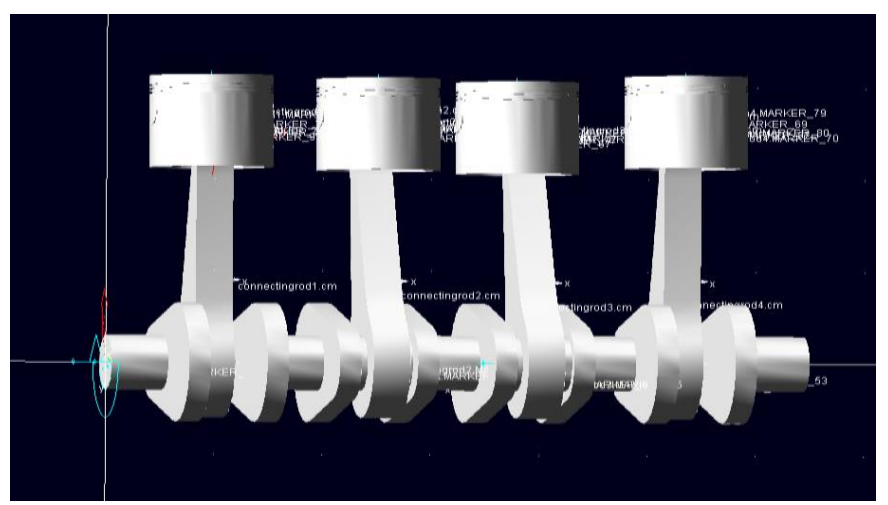

Figure 7: Simulation on ADAMS

\section{ANSYS MODEL}

Construct a three-dimensional representation of the object to be modeled and tested using the work plane coordinates system within ANSYS.

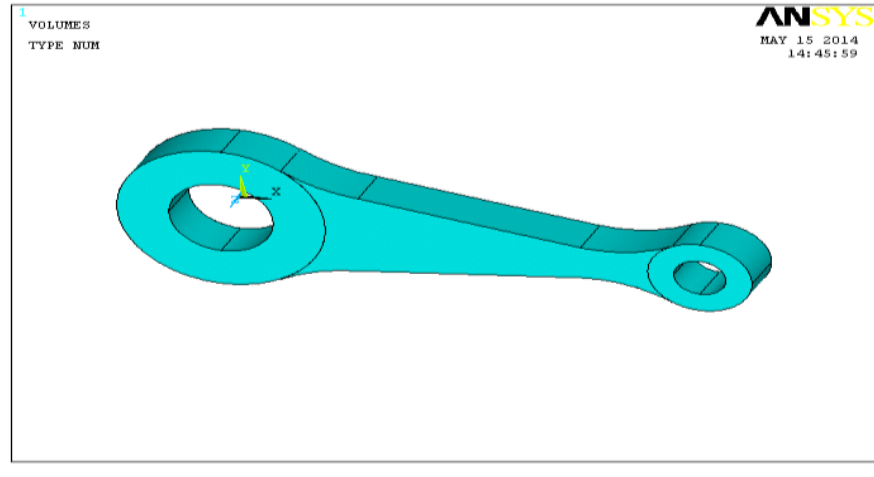

Figure 8: Modeling on ANSYS

\subsection{Material Properties at ANSYS}

Now that the part exists, define a library of the necessary materials that compose the object (or project) being modeled. This includes thermal and mechanical properties. Here the material selected is steel so we take material properties values are

$$
\begin{aligned}
& \text { Element type }=\text { SOLID } 185 \\
& \text { Young's modulus }=2.1 \mathrm{E} 6 \mathrm{~N} / \mathrm{mm}^{2} \\
& \text { Poisson's Ratio }=0.3 \\
& \text { Density }=7850 \mathrm{~kg} / \mathrm{m} 3
\end{aligned}
$$

\subsection{Selection of element type}

There is different type of element is available for use in our analysis software, ANSYS recommends using a current-technology element such as SOLID185 (KEYOPT (2) = 3). SOLID45 is used for the three-dimensional modeling of solid structures. The element is defined by 8 nodes having 3 (xyz) degrees of freedom at each node. A higher-order version of the SOLID45element is SOLID186. In this problem spring was modeled with element SOLID95/SOLID186. This is used for 3-D modeling of solid structures having 20 nodes. It can tolerate irregular shapes without as much loss of accuracy. SOLID186 elements have well-matched displacement shapes and are well suitable to model curved boundaries.

\subsection{Selection of Meshing}

Free meshing is a meshing method in which the faces and their boundaries are not necessarily respected unless there is a load, boundary condition [8]. The Patch independent meshing is useful when gross disfeaturing is needed in the model or when a very uniformly sized mesh is required. Virtual Topology can be used with patch self-determining meshing however the boundaries of the Virtual Cells may not be respected unless a scoped object exists.(VMESH, ALL)

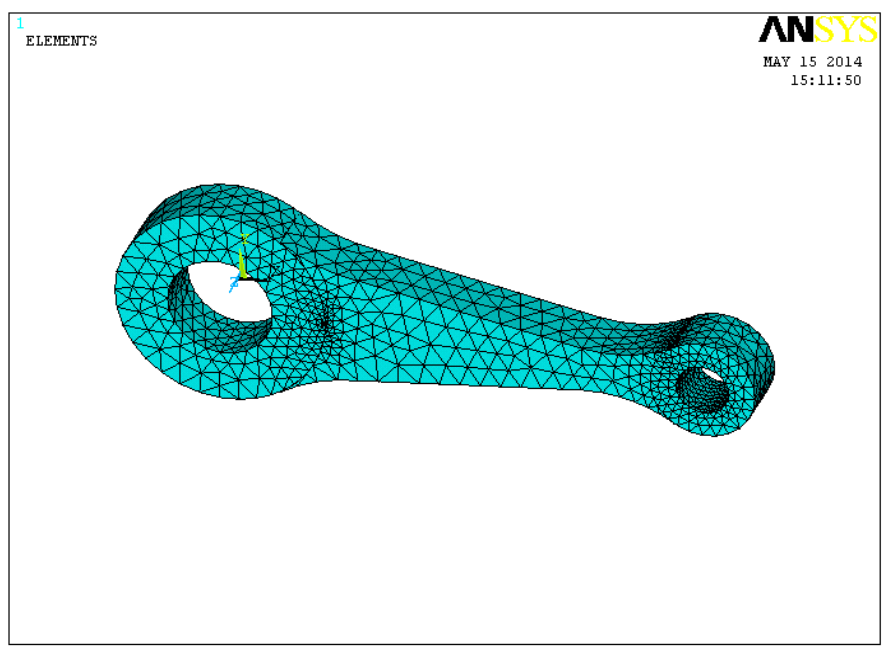

Figure 9: Free meshing of connecting rod

\subsection{Load Factors}

Once the system is completely designed, the last task is to burden the system with constraints, such as physical loadings or boundary conditions. 
As this connecting rod is used in the engine it is necessary to find out the load acting on the connecting rod in actual practice in static condition as well as in dynamic condition. Normally total weight of the reciprocating parts is about $1.3 \mathrm{Kg}$. And gas pressure is acting on the piston. By distributing the gas pressure connecting rod experience a force of $19205 \mathrm{~N}$ on the gudgeon area. And big side area is fixed (assumed).

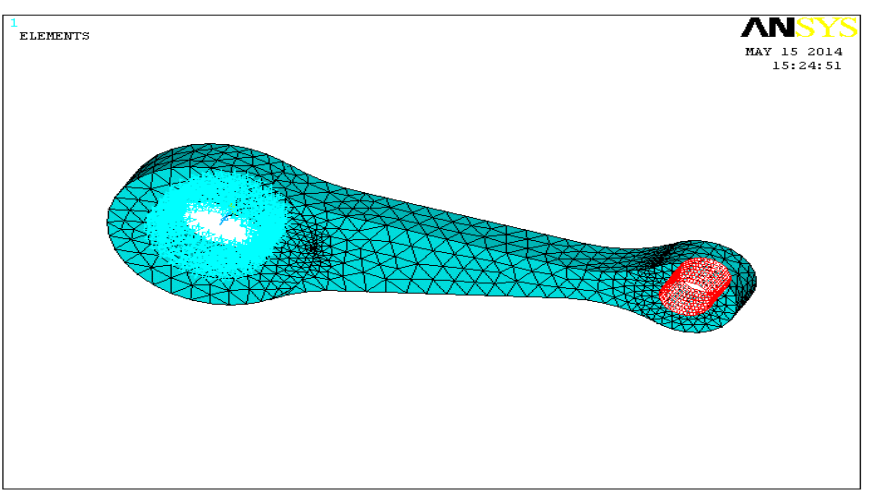

Figure 10: Load acting on the connecting rod

\section{RESULT AND DISCUSSION}

\subsection{Stress analysis}

This is actually a step, ANSYS needs to understand within what state the problem must be solved (steady state or transient). The linear static analysis was performed to determine the stress and strain results from the finite element model [9]. The material utilized in this work consists of a linear elastic, isotropic material. The choice of the linear elastic material model is essentially mandated. Model loading consist of the applied mechanical load, which is modeled as the load control and the displacement control. From the analysis, the inner area of the small end of the connecting rod experiences the largest stresses. The maximum shear stress distribution of the connecting rod is shown in figure. From the result, the maximum shear stress of value $181.846 \mathrm{~N}$ in $x y$ plane occurred at nodes on inner side.

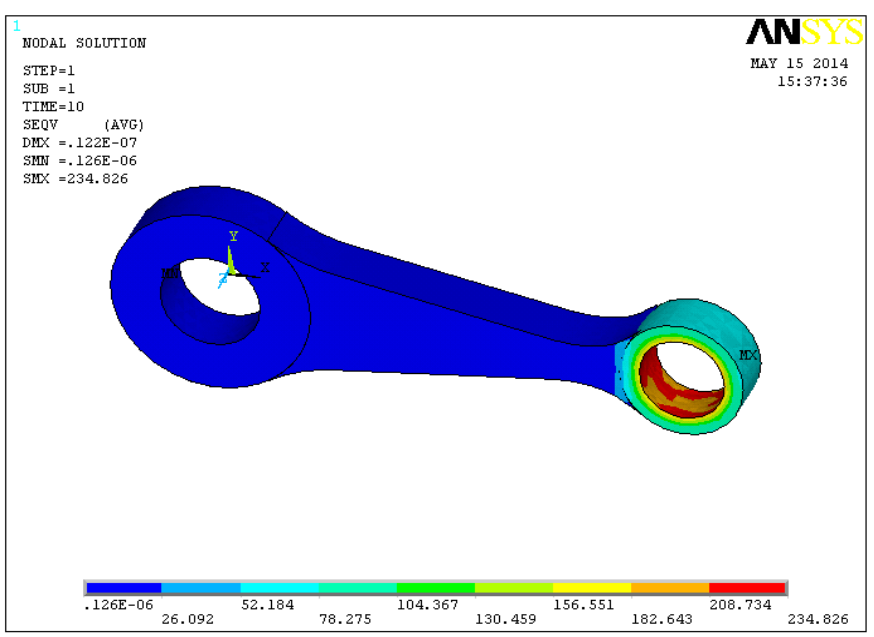

Figure 11: Von mises stress analysis on the connecting rod

\subsection{Fatigue}

\subsubsection{Introduction to Fatigue Analysis}

Fatigue analysis is an imperative aspect of component design. Typical yield stress design criteria miss the fatigue cycles seen in actual service use and hence can lead to improper design. Fatigue damage is a significant threat for developers, manufacturers and vendors of many products. A high number of recalls within the automotive industry and spectacular accidents of trains and air planes emphasize this. Fatigue damage bears high risk to human life and financial stability of manufacturers like OEMs in transportation industry. Failure due to cyclic loading of products during service also has a great impact on the image of a car manufacturer and therefore should be avoided. Fatigue is a complex issue with many different factors influencing durability and involving large scatter of individual parameters like loads or material data. Experimental as well as virtual methods are available to investigate the risk of a product to fail due to cyclic loading. Modern simulation methods, like the finite element method, require specific emphasis on modeling for the assessment of stresses suitable for further fatigue post-processing. This research paper gives insight into modern durability analysis covering topics from the required experimental tests to stress analysis using the FEM and an introduction into the different concepts for computational durability assessment. Statistical aspects of fatigue data and probability issues on product reliability will be covered as well.

Here we are using two different materials to find out the fatigue values, they are following:

\section{Carbon steel}

2. Aluminum alloy

It is also a material optimization process.

The maximum load acting on the connecting rod is $19205 \mathrm{~N}$

The minimum load acting on the connecting rod is $14871.984 \mathrm{~N}$ Numbers of cycles are 5000000 Numbers

Number of load steps are 4

\subsubsection{Fatigue Result Table}

\subsubsection{Location 1}

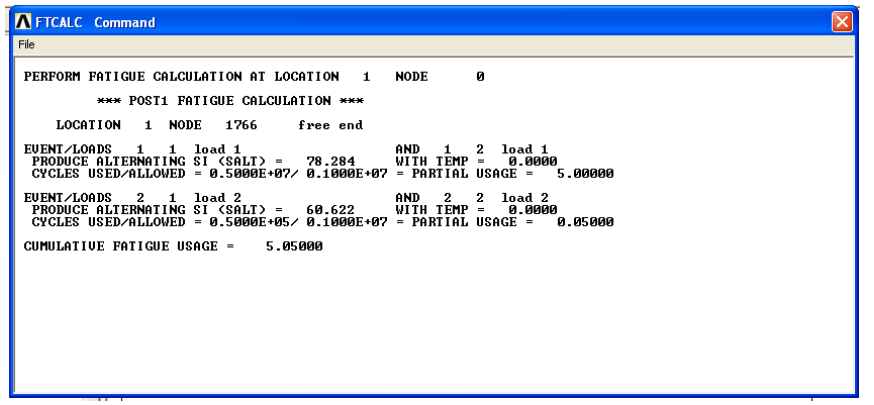

\subsubsection{Location 2}

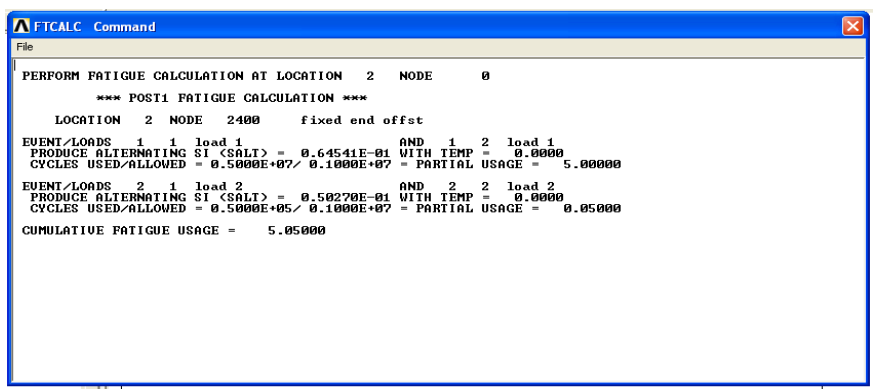

\section{CONCLUSION}

The medial surface of small end will be the critical surface whereby damage will initiate at the maximum stress condition. The stresses are high at the connecting rod shank, but stress distribution is relatively uniform. The maximum stress values are $126.42 \mathrm{MPa}$. The most significant location is at the transition area between the big end and connecting shank at maximum compression condition. The maximum stresses are $234.846 \mathrm{MPa}$. Safety factor is 4.31 . The fatigue life of the connecting rod is varying according to their material selection and his property. In order to increase the reliability of connecting rod, some improvement is carried out.

\section{REFERENCE}

[1] Khare, S., Singh, O.P., Bapanna Dora, K., Sasun, C. 2012. Spallinginvestigation of connecting rod. Engineering Failure Analysis, 19, 77-86.

[2] Roger, R. 1996. Fatigue failure of a connecting rod. Engineering Failure Analysis, 3, 13-28.

[3] Zhang, J.C., Li, X.H., Sun, G. 2006. CR design based on finite element analysis. Tractor \& Farm Transporter, 33, 27-30.

[4] Lee, M.K., Lee, H., Lee, T.S., Jang, H. 2010. Buckling sensitivity ofa connecting rod to the shank sectional area reduction. Materials and Design, 31, 2796-2803. 
[5] Kim, B., Kim, K. 2001. Thermo-elastohydrodynamic analysis ofconnecting rod bearing in internal combustion engine. Journal of Tribology, 123, 7-18.

[6] Griza, S., Bertoni, F., Zanon, G., Reguly, A., Strohaecker, T.R. 2009. Fatigue in engine connecting rod CR bolt due to forming laps. Engineering Failure Analysis, 16, 1542-1548.

[7] Griza, S., Bertoni, F., Zanon, G., Reguly, A., Strohaecker, T.R. 2009. Fatigue in engine connecting rod bolt due to forming laps. Engineering
Failure Analysis, 16, 1542-1548.

[8] Kima, H.S., Kimb, T.G., Chung, T.J., Kim, H.S., Hong, S.J. 2010. Fatigue characteristics of high strength C70S6 and SMA40Steels. Materials Science and Engineering: A, 527, 2813-2818.

[9] Yin, F., Wang, G.X., Hong, S.Z., Zeng, Z.P. 2003. Technological of an air compressor. Journal of Materials Processing Technology, 139, 462-464. 